\title{
A Customer Segmentation Methodology for Energy Efficiency Products
}

\author{
Rafaila Grigoriou, Fanny Lindberg, and Ying Pang
}

\begin{abstract}
Energy efficiency services and programs are essential in the energy transition, but these are often costly and have low uptake rates. This paper proposes a customer segmentation methodology for energy efficiency solutions, which characterizes customers according to similarities of demographic factors and identifies key customer segments more engaged with offers. This allows for tailoring of energy efficiency solutions. The methodology is applied to datasets from the post-pilot survey results of three energy efficiency demonstrations in Austria, Italy and Sweden as a part of the Horizon 2020 FLEXICIENCY project. The segmentation results show that Environmentalists and Rationalists are the dominant groups with higher usage and satisfaction rates. It furthermore concludes that, based on the Swedish case study, Environmentalists followed by Rationalists have greater achievement of energy savings through energy efficiency services, $4,73 \%$ and $4,04 \%$ respectively over one year.
\end{abstract}

Index Terms-Customer segmentation, energy efficiency products, customer characteristics, energy savings.

\section{INTRODUCTION}

Although a constant progress of technology is closely associated with an ongoing improvement of energy efficiency solutions, offering a variety of friendly-priced and easy-to-use products and services, little progress has been reported related with uptake rates of these types of products. Low uptake rates have been observed in both residential and commercial sector for opt-in energy pilots during past years [1], with an average rate of about $1.5 \%$ [2], whereas participant recruitment is even challenging in financed energy efficiency programs [3]. A study has found that many energy efficiency programs reach less than $0.1 \%$ of their targeted customers annually [4]. Even though there are cases with higher participation rates around $15 \%-20 \%$ [2], they are only the minority [5]. Energy efficiency programs are usually costly, requiring state-to-art technology, big data handling and effective marketing. The savings associated with energy efficiency services can be promising depending on their types [6], [7] and frequency [8], [9], however, the number of engaged end-consumers is more important to maximize the cost/benefit of programs [10]. Increased uptake

Manuscript received July 15, 2019; revised October 8, 2019. This project has received funding from the European Union's Horizon 2020 research and innovation program under grant agreement $n^{\circ} 646482$.

Disclaimer: This paper reflects the FLEXICIENCY consortium view and the European Commission (or its delegated Agency INEA) is not responsible for any use that may be made of the information it contains.

Rafaila Grigoriou is with VaasaETT, Helsinki, 00500 Finland (e-mail: rafaila.grigoriou@vaasaett.com).

Fanny Lindberg and Ying Pang are with Vattenfall, Stockholm, 16992 Sweden (email: fanny.lindberg@vattenfall.com, ying.pang@vattenfall.com). rates would directly benefit energy efficiency programs within both monetary and environmental scope, and consequently there is a need to investigate effective and efficient recruiting methods.

A modern approach into recruitment suggests that directly focusing on consumers who are more likely to be interested in energy efficiency can bring higher participation rates with fewer resources [4]. Customer segmentation is defined as grouping customers into segments based on a set of factors related with consumers' energy behaviour, mindset, age, education and income levels [7]. Then segmentation-based recruitment is either used to identify the targeted customers who are more likely to be attracted by offered services, or create customized marketing strategies to communicate with a variety of consumer segments and drive their attention. A study about opt-in and opt-out programs indicates that there is limited benefit of recruiting non-genuinely-interested consumers into energy efficiency programs [11]. However, some Opower studies argue that, for participants discontinued after two-year participation in an opt-out energy monitoring program, there still exists comparatively persistent effects on energy efficiency with slow descent by only $10 \%-20 \%$ per year [12]. Beginning with [13], relations of participant characteristics and uptake rates have been widely analysed with a purpose to design cost-effective energy efficiency programs for all customer classes, and [14], [15] test a handful of crucial characteristics including household size, age, income and education level. A segmentation recruitment approach is applied to identify target groups by analysing interview answers randomly collected [16]. Furthermore, a series of market research studies are conducted to recognize customers who act as primary targets of energy efficiency programs [17], [18].

This paper proposes a methodology of customer segmentation for energy efficiency solutions, which can characterize consumers and identify key customer groups for the tailoring of energy efficiency solutions. The analysis performed in this paper is developed within the Horizon 2020 FLEXICIENCY project and uses data from three demonstrations in Austria, Italy and Sweden. The results show the importance of satisfactory segmentation and the generally applicable method is presented in this paper. Additionally, a proper consumer segmentation contributes to higher achievement of energy efficiency. This paper takes the analysis a step further by leveraging electricity consumption data available from the Swedish demonstration and explores the drivers behind the derived groups of consumers.

The paper is structured as follows: Section II shortly presents the data sources, followed by a thorough description of methodology in Section III. Section IV summarizes the results, including the comparison of three demonstrations and 
detailed presentation of Swedish case study. Finally, Section $\mathrm{V}$ concludes along with recommendations and future work discussion.

\section{DATA DESCRIPTION}

This study is based on the data collected during FLEXICIENCY project, in which three energy efficiency demonstrations were designed and implemented in Austria, Italy and Sweden, respectively. The Austrian demonstration includes two residential participant groups with/without local generation, in which advanced monitoring services are offered to 178 households. The Italian demonstration consists of a residential group with/without solar PVs with consumption monitoring services, sample size 151 households. The Swedish demonstration is the largest demonstration with 2,508 consumers using the service "Energichecken", depicted by Fig. 1. Energichecken is a mobile application (available on App Store and Google Play Store) developed using automatic meter reading and real-time data. The customers are provided continuous access to household consumption, and advice and alerts to address behavioral changes. By combining external and internal data sources, new patterns in customer data can be detected and used for forecasting, insight messages and tailored offers.

After the completion of all three demonstrations, post-pilot surveys have been conducted via online questionnaires. The post-pilot survey results are used as input of the presented methodology.

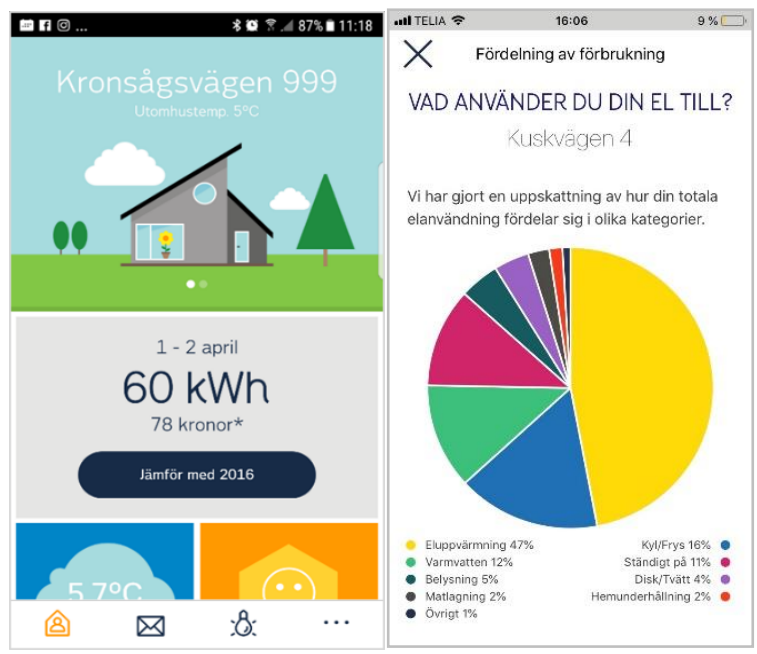

Fig. 1. Screenshot of Energichecken.

\section{Methodology}

An overview of the analysis methodology pipeline using post-pilot survey results as data inputs is presented in Fig. 2.

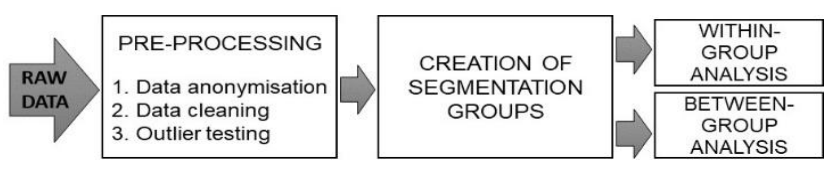

Fig. 2. Analysis methodology pipeline.

\section{A. Data Pre-processing}

The first step of the analysis is data pre-processing to protect privacy information and provide the data for analysis with high quality. This step includes three stages: data anonymization, data cleaning and outlier testing. First and foremost, raw data sets are anonymized so that survey participants whom the data and analysis conclusions describe can no longer be identified. Next, data cleaning is performed to identify, delete and modify the coarse or inaccurate records, hence the data is consistent and accurate. The processes involve discarding half-answered questionnaires, integrating self-written options in the questions so that similar answers are treated as one category, and checking that text-field replies are consistent with the question's acceptable answer ranges. Finally, outlier testing is employed to detect values markedly deviating from others, e.g. caused by fill-in mistakes or data entry errors. Boxplot with Tukey's method is used to display outliers, and only extreme outliers are excluded from the dataset.

\section{B. Segmentation Grouping}

Survey participants are classified into four types of consumer segments according to their mindset, awareness and sensitivity towards environmental matters. The methodology for determining a participant profile is based on a scoring matrix, in which the individual answers give points to each of different segments and the participant is then assigned to the segment with the highest score. All questions involved in the segmentation grouping should be answered on scale 1 to 5 , where 1 indicates the lowest agreement and 5 represents the highest agreement with the statement in question. Table I illustrates the relation of determinant questions with the four segments, where $\mathrm{H}, \mathrm{M}$ and $\mathrm{L}$ indicated High, Medium and Low, respectively. The full participant survey and weighting matrices used for the grouping can be found in Appendices 6 and 8 of FLEXICIENCY D3.2 respectively.

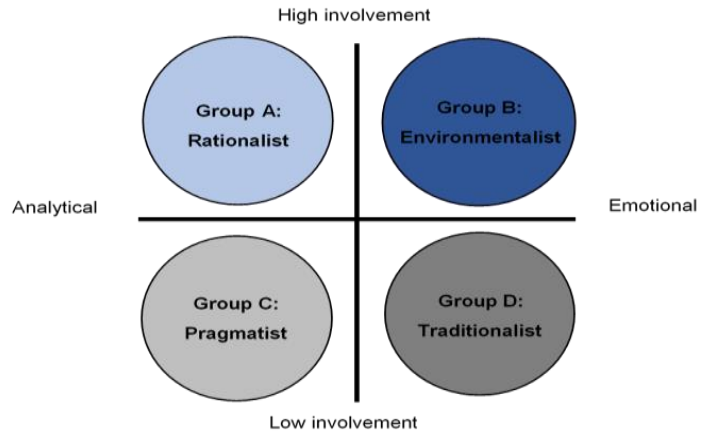

Fig. 3. Consumer segments.

The four segments are A: Rationalists, B: Environmentalists, C: Pragmatists and D: Traditionalists, shown as Fig. 3. By studying people's psychological backgrounds, Rationalists tend to question information provided, especially if it conflicts their own understanding. They form their opinions based on scientific evidence and if they have first established an argumentation based on hard facts, they are very hard to convince of something else. Environmentalists have a strong involvement in climate issues and are generally acting on a more emotional background; in this respect they do not need to be overwhelmed by facts but more motivated by being ensured 
that they are doing the right thing. Pragmatists, like Rationalists, focus on facts and scientific evidence, and they are mostly interested in the present and the immediate results of their actions. They are willing to listen and change their mind, if they see an immediate benefit in doing so. Finally, Traditionalists follow their instincts and would say yes to a suggested change just to avoid conflict in many instances.

TABLE I: RELATIONSHIPS BETWEEN SEGMENTATION GROUPS AND DETERMINANTS

\begin{tabular}{|c|c|c|c|c|}
\hline Determinants & $\mathbf{A}$ & B & $\mathbf{C}$ & $\mathbf{D}$ \\
\hline I think everyone should "do their bits" for the environment & $\mathrm{H}$ & $\mathrm{H}$ & $\mathrm{L} / \mathrm{M}$ & $\mathrm{L} / \mathrm{M}$ \\
\hline I am concerned about energy price rises & $\mathrm{H}$ & $\mathrm{H}$ & M & $\mathrm{L}$ \\
\hline The information has helped us reduce electricity usage & M & $\mathrm{H}$ & M & $\mathrm{L} / \mathrm{M}$ \\
\hline I am interested in making my home more environmentally friendly & $\mathrm{n} / \mathrm{a}$ & $\mathrm{H}$ & $\mathrm{L} / \mathrm{M}$ & $\mathrm{L} / \mathrm{M}$ \\
\hline I am interested in the cool technology provided in the program & $\mathrm{M} / \mathrm{H}$ & $\mathrm{L}$ & $\mathrm{M} / \mathrm{H}$ & $\mathrm{L}$ \\
\hline We feel we are making a positive contribution to the environment & $\mathrm{H}$ & $\mathrm{H}$ & $\mathrm{M} / \mathrm{H}$ & M \\
\hline My friends / neighbours are taking action in terms of saving energy & M & $\mathrm{H}$ & $\mathrm{H}$ & $\mathrm{L} / \mathrm{M}$ \\
\hline How would you feel if you could no longer use the service? & $\mathrm{M} / \mathrm{H}$ & $\mathrm{L}$ & $\mathrm{L}$ & $\mathrm{H}$ \\
\hline Assuming a reasonable price, how likely would you be to purchase the service? & $\mathrm{L}$ & $\mathrm{H}$ & $\mathrm{L} / \mathrm{M}$ & $\mathrm{M} / \mathrm{H}$ \\
\hline I am always looking for ways to reduce my energy bills & $\mathrm{H}$ & $\mathrm{H}$ & $\mathrm{L}$ & M \\
\hline
\end{tabular}

\section{Within Group Analysis}

The purpose of within group analysis is to understand the characteristics of people comprising these four groups, investigate their demographic characteristics and explore how they reacted to the demonstration services. It consists of simple statistical analysis based on datasets to create the profiles of groups. The detailed questions for within group analysis are shown in Table II with results.

\section{Between Group Analysis}

Between group analysis is used to identify demographic characteristics of participants that differ amongst the segments with statistical evidence, which provides valuable insights of the recruitment of future customers for the tested services. This is performed by running cross-tabulation Chi-square tests between the segmentation groups (variable 1) and selected survey questions (variable 2). According to Chi-square test results, the null hypothesis, that is "variable 1 is independent from variable 2 ", can be rejected or accepted. Here, the analysis uses the same data as the one for within group analysis, and test results are assessed given three statistical significance levels $90 \%, 95 \%$ and $99 \%$.

\section{E. Energy Efficiency}

Smart meter electricity consumption data of the Swedish demonstration is used to investigate energy efficiency. Energy savings are analyzed for two selected house types, main houses and apartments, and excluding summer houses as they are expected to behave differently. Only differences in energy reduction across customer groups are investigated, in contrast to housing types. A two-stage process is employed for processing consumption data. Stage one involves statistical examination of data to deal with missing or inaccurate information. Stage two includes data aggregation and weather correction. The electricity consumptions are weather-corrected using heating degree-days [19] on monthly basis so that values are comparable temporally and spatially. Moreover, energy efficiency is measured as reduction of electricity consumption. Four energy savings indicators are calculated per household: monthly electricity reduction $(\mathrm{kWh})$; monthly electricity reduction per capita $(\mathrm{kWh}$ per capita); monthly electricity reduction per square meter $(\mathrm{kWh} /$ $\mathrm{m} 2)$; and monthly electricity saving (\%).

A one-way analysis of variance (ANOVA) is performed for comparing the average electricity savings between customer segmentation groups and to test the statistical significance of the difference. Note that two required assumptions, that the data are normally distributed and the variance across groups are homogeneous, must be verified. With unequal sample size in each group, Type-III sums of squares are used for running ANOVA in an unbalanced design.

\section{RESUlTS}

After data pre-processing and preparation, the data sets for segmentation include 113 participants from the Austrian demonstration, 125 consumers from the Italian demonstration and 386 customers from the Swedish demonstration.

\section{A. Overall Results}

The segmentation grouping results are illustrated in Environmentalists and Traditionalists are two largest segments in Italian demonstration, while both Austrian and Sweden demonstrations show Environmentalists and Rationalists are dominant segments. This variation might be related to the information provided via advanced monitoring services or the recruitment strategy itself. A great focus on numbers and scientific facts attracts Rationalists more, while information related to environmental impacts directs towards Environmentalists.

The variables with statistically significant dependence on groups are education level, residence type, monthly electricity bill, usage, satisfaction and recommendation rate, summarized in Table II. It is noticed that for Italian demonstration, satisfied participants are more likely with lower level of education compared with other categories, indicating that advance monitoring services can be seen as educational tools to extend energy-related knowledge. The evidence supports that people with high electricity bills seem to be more willing to reduce consumption, and those unaware of their electric bill pay more attention on consumption with 
the tested service. In terms of user activity, Environmentalists are found to access the provided services more frequently, in which the Swedish demonstration shows that Environmentalists use the services at least on weekly basis. All demonstrations recognize that Environmentalists and Rationalists are associated with the higher satisfaction and recommendation rates, and the willingness to recommend is positively correlated with participant satisfaction as expected Some of our results align with the findings of previous work [14] despite different variables examined and methodology employed. More detailed results can be found in FLEXICIENCY D3.2.

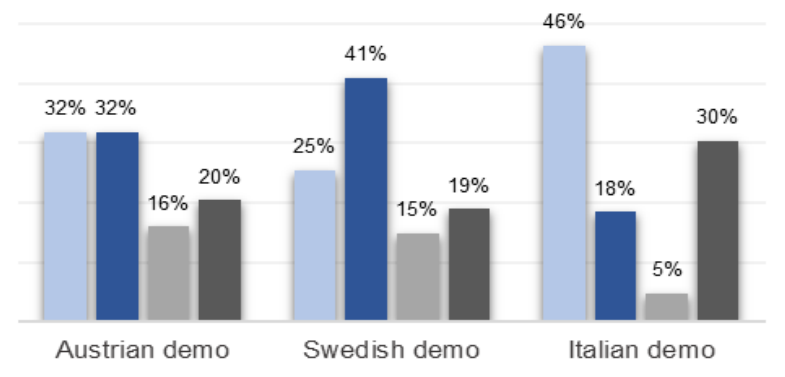

$\approx$ A: Rationalist $\quad$ B: Environmentalist $\equiv$ C: Pragmatist $\square$ D: Traditionalist

Fig. 4. Segmentation grouping results.

TABLE II: SUMMARY OF CROSS-TABULATION RESULTS

\begin{tabular}{lccc}
\hline \hline Determinants & Austria & Italy & Sweden \\
\hline $\begin{array}{l}\text { Number of residents in } \\
\text { the household }\end{array}$ & & & \\
$\begin{array}{l}\text { Education level } \\
\text { Residence type }\end{array}$ & & $\cdot$ & \\
$\begin{array}{l}\text { Rented/Owned } \\
\text { household } \\
\text { Primary heating source }\end{array}$ & & & n/a \\
$\begin{array}{l}\text { Income level } \\
\text { Average monthly } \\
\text { electricity bill }\end{array}$ & $\mathrm{n} / \mathrm{a}$ & $\mathrm{n} / \mathrm{a}$ & $\cdot$ \\
$\begin{array}{l}\text { Usage rate } \\
\text { Satisfaction rate }\end{array}$ & $\cdot$ & $\cdot$ & $\cdot$ \\
Recommendation rate & $\cdot$ & $\cdot$ & $\cdot$ \\
\hline \hline
\end{tabular}

\section{B. Case Study: Swedish Demonstration}

\section{1) Residence type}

The residence type is identified as an important factor to segment consumers into groups. The stacked bar chart as Fig. 5 compares the residence type and groups. Over $70 \%$ of households are main houses for all groups, while larger proportions of summer houses and apartments are found with group A and B which also contain a wider variety of residence types.

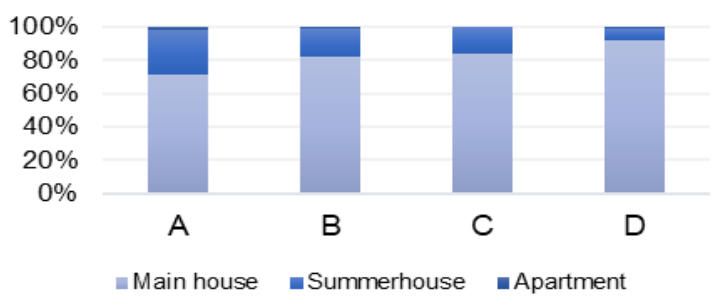

Fig. 5. Residence type distribution among segments.

\section{2) Monthly electricity bill}

The analysis shows a significant difference in the monthly electricity bill among groups, and that changing consumers' behavior relies on awareness of monthly consumption. Fig. 6 illustrates that group B with higher monthly electricity bills, in which $50 \%$ of households pay over 2000 sek, while the highest range for other groups is 1001-2000sek per month. Interestingly, only group B contains people unaware of their electricity bill. The category of monthly payment $1001-2000$ sek is covered by $41 \%$ of group B and $98 \%$ of group $\mathrm{A}$, however, for group $\mathrm{C}$ and $\mathrm{D}$, more than $80 \%$ of customers belong to the lowest available scale, 500-1000sek.

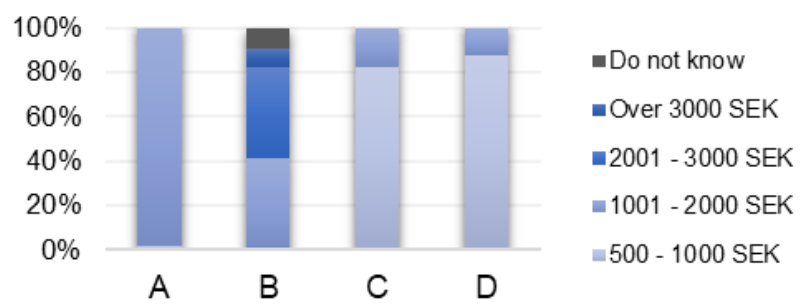

Fig. 6. Monthly electricity bill distribution among segments.

\section{3) Usage rate}

The Swedish survey allows for a greater granularity of service usage data in terms of user activity and frequency information. Fig. 7 shows that group B participants use the provided services more often, at least on weekly basis. For group A, $44 \%$ of participants make full use of services weekly and $56 \%$ of them access the services on monthly basis. Group $\mathrm{C}$ has the least usage frequency that $74 \%$ of participants rarely or never make actual use of offered services.

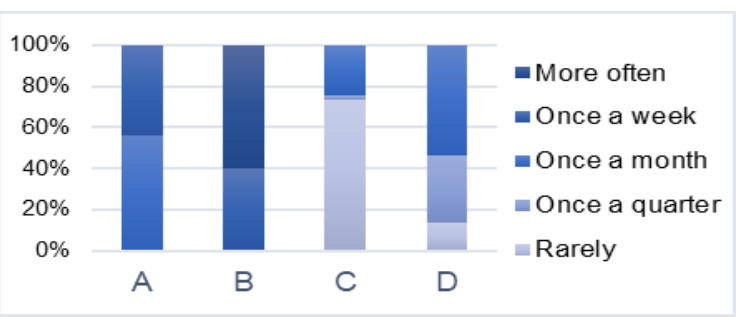

Fig. 7. Participant activity among segments.

\section{4) Satisfaction rate}

Satisfaction rate shares a similar pattern with usage rate, shown as Fig. 8. Group B is the most satisfied with the provided services, $23 \%$ are very satisfied and $77 \%$ are satisfied. Group A follows with no dissatisfied answer, while $42 \%$ are satisfied and $58 \%$ are neutral. On the contrary, no satisfied participants are included in group $\mathrm{C}$ and $\mathrm{D}$, which $67 \%$ and $12 \%$ of respondents respectively have declared to be dissatisfied by the provided services.

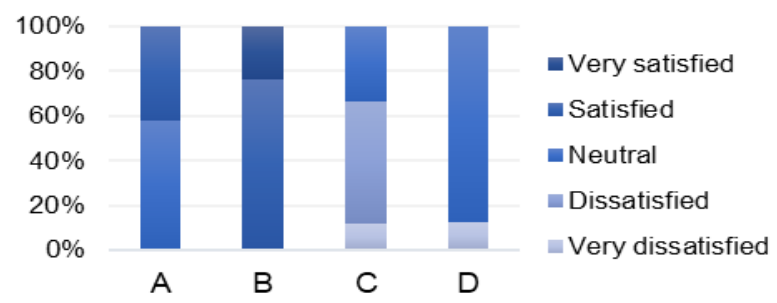

Fig. 8. Participant satisfaction among segments.

\section{5) Recommendation rate}

The results are analogous to satisfaction rates results. Fig. 9 illustrates that $97 \%$ of group A participants are likely to recommend the services, while, for group B, $19 \%$ and $81 \%$ 
are likely and very likely to recommend to others, respectively. Furthermore, the majority of group D, 84\%, consist of neutral participants, and $68 \%$ of people from group $\mathrm{C}$ are not willing to recommend the services.

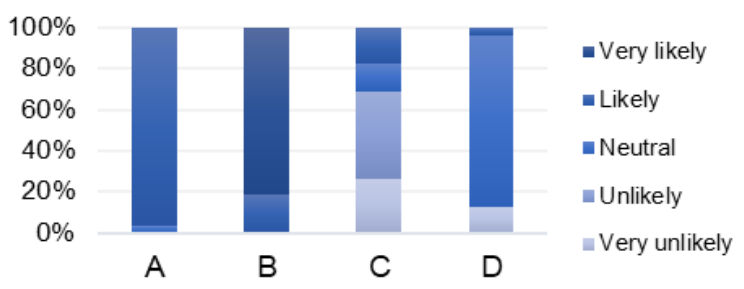

Fig. 9. Participant recommendation rate among segments.

TABLE III: SUMMARY OF ANOVA TESTS RESULTS

\begin{tabular}{|c|c|c|c|c|c|}
\hline \multirow{2}{*}{ Measurements } & \multicolumn{4}{|c|}{ Customer Segmentation } & \multirow[b]{2}{*}{ b } \\
\hline & $\mathbf{A}$ & B & $\mathbf{C}$ & D & \\
\hline Sample size (\#) & 48 & 86 & 32 & 42 & \\
\hline Avg. household size (\#) & 2.4 & 2.6 & 2.5 & 2.8 & \\
\hline Avg. house area $\left(m^{2}\right)$ & 149 & 149 & 158 & 165 & \\
\hline $\begin{array}{l}\text { Avg. monthly reduction } \\
(\mathrm{kWh})\end{array}$ & 57.5 & 72.8 & 25.1 & 35.5 & $* *$ \\
\hline $\begin{array}{l}\text { Avg. monthly reduction per } \\
\text { capita }(\mathrm{kWh})\end{array}$ & 19.5 & 32.3 & 17.0 & 19.5 & $* *$ \\
\hline $\begin{array}{l}\text { Avg. monthly reduction per } \\
\text { square meter }(\mathrm{kWh})\end{array}$ & 0.44 & 0.61 & 0.13 & 0.36 & $* * *$ \\
\hline $\begin{array}{l}\text { Avg. monthly reduction } \\
(\%)\end{array}$ & 3.0 & 3.3 & 1.6 & 1.3 & $*$ \\
\hline
\end{tabular}

${ }^{\mathrm{b}}$ The last column provides significance of ANOVA tests given significant levels $90 \%, 95 \%$ and $99 \%$.

TABLE IV: POST HOC COMPARISON OF TOTAL REDUCTION CONTRIBUTED BY SEGMENTS

\begin{tabular}{lccccc}
\hline \hline \multirow{2}{*}{ Percentage \% } & \multicolumn{4}{c}{ Customer Segmentation } & \multirow{2}{*}{ Total } \\
\cline { 2 - 5 } & A & B & C & D & \\
\hline $\begin{array}{l}\text { By sample size for total } \\
\text { number of households }\end{array}$ & 23 & 41 & 16 & 20 & 100 \\
$\begin{array}{l}\text { Annual energy saving } \\
\text { By contribution for total }\end{array}$ & 4.02 & 4.73 & 1.57 & 2.55 & 3.64 \\
energy reduction & 25 & 53 & 7 & 14 & 100 \\
\hline \hline
\end{tabular}

\section{6) Energy efficiency}

There are 386 survey participants for Swedish demonstration, of which 208 households have validated consumption after data processing. The data covers 178 postal codes with time span of 2 years. Table III summarizes the descriptive statistics and energy savings indicators per segmentation group. Notice that greater values of savings are desirable, indicating an increase in energy efficiency with "Energichecken". The highest energy reduction is obtained by group $\mathrm{B}$, followed by group $\mathrm{A}$. The lowest results are found in group $\mathrm{C}$ and group $\mathrm{D}$ in terms of energy savings in $\mathrm{kWh}$ and percentage respectively. The significant $\mathrm{p}$-values of ANOVA allow us to safely reject the null hypothesis that all consumer segments perform equally in reducing electricity consumption. The results indicate that customer segmentation can impact significantly energy savings and support the conclusions from the survey analysis of user activity and satisfaction rates. Furthermore, Table IV presents an overview of annual energy reduction per segment group, along with the proportion to total reduction. For group B, a $4.73 \%$ reduction in electricity consumed by $41 \%$ of total households results in approximately $1.94 \%$ total reduction, which contributes for $53 \%$ of total energy saving. Furthermore, $23 \%$ of households belong to group A with $4.02 \%$ electricity consumption reduction, which contributes for $25 \%$ of total energy saving annually. This suggests that energy efficiency services are more effective with proper consumer segmentation and customer segment targeting.

\section{CONCLUSION AND DISCUSSION}

In this work, a methodology for customer segmentation is proposed. The methodology is applied to classify participants into four segmentation groups: Rationalists, Environmentalists, Pragmatists and Traditionalists. The performance of this method is compared based on datasets in the form of post-pilot survey results coming from three energy efficiency demonstrations, in Austria, Italy and Sweden, as part of the H2020 FLEXICIENCY project.

The analysis shows that Rationalists and Environmentalists are the most dominant segments in the examined demonstrations, who make full use of services more actively and are consequently more satisfied by the tested services. Hence these groups, especially Environmentalists, should be considered as the target customers of recruitment campaigns for energy efficiency products. On the other hand, the results suggest that Pragmatists are least represented and are difficult to be recruited for such services in all three demonstrations. As the analysis shows, Pragmatists are more likely to be inactive and dissatisfied by such services, thus they are not given top priority to similar services for promotion. In other words, they might be attracted by another engagement strategy and/or products.

The results of segmentation grouping are investigated in detail, to identify a handful of important demographic characteristics including education level, residence type and the awareness of monthly electricity consumption/bill. By further analysing energy reduction based on customer segmentation, the increase of energy efficiency was found to be significant between the groups. Environmentalists followed by Rationalists significantly increased energy efficiency of their households during the treatment period. It can be concluded that energy efficiency products are most effectives in segments with higher energy consciousness. These segments have the highest potential and probability to decrease their energy use.

In conclusion, this paper proposes a methodology for customer segmentation that contributes to more effective energy efficiency solutions. In the future, the work will be extended with more data available as "Energichecken" continues as a commercial offer in Sweden. The increasing availability of granular energy data and improved consumer segmentation tools go hand in hand, which creates the opportunity for energy providers to better understand what customers really need and how they behave. This certainly enhances the competitiveness of energy market players and more importantly benefits energy customers, demonstrated by FLEXICIENCY project.

\section{CONFLICT OF INTEREST}

Rafaila Grigoriou declares that she has no conflict of interest. Fanny Lindberg declares that she has no conflict of interest. Ying Pang has been directly employed by ÅF Pöyry Group. 


\section{AUTHOR CONTRIBUTIONS}

Rafaila Grigoriou developed the methodologies and performed the analysis for Austrian and Italian cases. Fanny Lindberg initiated the extended study, supervised the project and was responsible for the development of Swedish demonstration. Ying Pang collected the data and performed the analysis for Swedish case. All authors shaped the study, interpreted the results and drew conclusions to develop the suggested methodology along with writing of final manuscript.

\section{ACKNOWLEDGMENT}

We would like to thank Christophe Dromacque and Thomas Mikkelsen for the design of survey and segmentation grouping methodology respectively. We also would like to express our great appreciation to Athanasia Louloudi, Christina Svalstedt and Dag Wästlund who play important roles in Swedish demonstration of H2020 FLEXICIENCY project.

\section{REFERENCES}

[1] L. Berry, "A review of the market penetration of US residential and commercial demand-side management programmes," Energy Policy, vol. 21, no.1, pp. 53-67, 1993.

[2] L. Bird and E. Brown, Trends in Utility Green Pricing Programs (2005) National Renewable Energy Laboratory Technical Report, United States, 2006.

[3] M. Fowlie, M. Greenstone, and C. Wolfram, "Do energy efficiency investments deliver? Evidence from the weatherization assistance program," The Quarterly Journal of Economics, vol. 133, no. 3, pp. 1597-1644, 2018.

[4] M. Fuller, Enabling Investments in Energy Efficiency: A Study of Programs that Eliminate First Cost Barriers for the Residential Sector, Burlington: Efficiency Vermont, 2008.

[5] P. Schwarz, J. Suzuki, and D. Mangan, Oregon Residential Awareness and Perception Study, Research Into Action Inc. Residential Programe Solution Center, 2014.

[6] J. Kelly and W. Knottenbelt, "Does disaggregated electricity feedback reduce domestic electricity consumption?" A Systematic Review of the Literature, 2016.

[7] J. Stromback, C. Dromacque, and M. H. Yassin, The Potential of Smart Meter Enabled Programs to Increase Energy and Systems Efficiency: A Mass Pilot Comparison VaasaETT, 2011.

[8] C. Dromacque, R. Grigoriou, T. Mikkelsen, H. Launonen, and L. Oikonomou, Report: The Role of Data for Consumer Centric Energy Markets and Solutions ESMIG, 2019.

[9] B. Karlin, J. F. Zinger, and R. Ford, "The effects of feedback on energy conservation: A meta-analysis," Psychological Bulletin, vol. 141, no. 6 , p. 1205, 2015.

[10] C. Wiese, A. Larsen, and L. L. Pade, "Interaction effects of energy efficiency policies: A review," Energy Efficiency, vol. 11, no. 8, pp. 2137-2156, 2018.

[11] A. M. Borchers, J. M. Duke, and G. R. Parsons, "Does willingness to pay for green energy differ by source?" Energy Policy, vol. 35, no. 6 , pp. 3327-34, 2007.

[12] H. Allcott and T. Rogers, "The short-run and long-run effects of behavioral interventions: Experimental evidence from energy conservation American Economic Review, vol. 104, no. 10, pp. 3003-3037, 2014.

[13] C. E. Hoicka, P. Parker, and J. Andrey, "Residential energy efficiency retrofits: How program design affects participation and outcomes," Energy Policy, vol. 65, pp. 594-607, 2014.

[14] S. F. Gamtessa, "An explanation of residential energy-efficiency retrofit behavior in Canada," Energy and Buildings, vol. 57, pp. 155-64, 2013.

[15] I. G. Hamilton, A. J. Summerfield, D. Shipworth, J. P. Steadman, T. Oreszczyn, and R. J. Lowe, "Energy efficiency uptake and energy savings in English houses: A cohort study," Energy and Buildings, vol. 118, pp. 259-276, 2016.

[16] J. S. Peters, J. Suzuki, and M. Spahic, Final Report Oregon Residential Awareness and Perception Study Research into Action Inc., Residential Programe Solution Center, 2009.

[17] A. Albert and M. Maasoumy, "Predictive segmentation of energy consumers," Applied Energy, vol. 177, pp. 435-448, 2016.

[18] C. Fogel, Vision: A New Norm of Energy Behavior - Smart Energy living Presentation, California Public Utilities Commission, April 9, 2020.

[19] T. Day, Degree-Days: Theory and Application, CIBSE (England), 2006.

[20] P. Lewis, R. Grigoriou, C. Dromacque, A. Bogacka, and S. Xu, Assessing the Potential of Energy Consumption Feedback in Norway, Norwegian Water Resources and Energy Directorate (NVE), 2014.

[21] C. Dromacque, T. N. Mikkelsen, and R. Grigoriou, Assessing the Potential of Home Automation in Norway, Norwegian Water Resources and Energy Directorate (NVE), 2017.

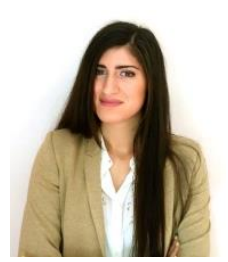

Rafaila Grigoriou holds a diploma in electrical and computer engineering from Aristotle University of Thessaloniki (AUTH), Greece and a M.Sc. in statistics and modeling from the Mathematics Department of AUTH.

She has been working in VaasaETT since 2013, in the beginning as a data analyst and currently as a data analysis manager; since 2017 she is leading the company's Greek Department in Thessaloniki. Her fields of expertise lie on data science, machine learning and feature engineering. During her studies and work life she has acquired technical skills on several programming languages (e.g. python, MATLAB, Java) and data analysis tools (e.g. SPSS, Weka), which she can use to analyse raw or structured data, while at the same time she has gained knowledge related with energy markets, energy pricing and energy efficiency. She has implemented the analysis for various VaasaETT public reports [6], [20], [21] and EU-funded research projects (FP7-CASSANDRA, FP7-eBADGE, H2020-FLEXICIENCY, H2020-ASSIST etc.) and published her master thesis research work on time-series analysis, feature extraction and critical point detection in Journal of Biomechanics.

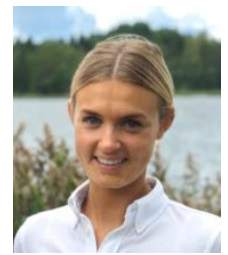

Fanny Lindberg holds a M.Sc. in engineering design and product realization with focus on sustainable energy engineering from the School of Industrial Technology and Management at the Royal Institute of Technology (KTH), Stockholm, Sweden, 2017.

She has been working at Vattenfall R\&D since 2017, in the beginning as an international trainee $R \& D$ engineer and currently as a project manager $R \& D$ engineer, Stockholm. Lindberg's field of expertise is project management for ICT solutions in the energy sector. Her focus is specifically on smart charging, data-based customer services and business development in new energy technologies with a strong customer focus. During her work life she has acquired skills in project management through several development projects and was project manager for the Swedish demonstration in the H2020-FLEXICIENCY project and also the KPI work package. She has published her bachelor thesis on performance improvement using phase changing material in a combined water heater in REHVA Journal October 2016.

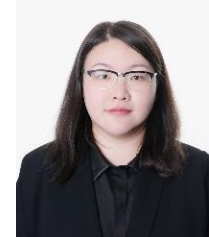

Ying Pang holds a licentiate in mathematical statistics with the focus on high-dimensional statistics and predictive analytics from the Division of Mathematical Statistics, Department of Mathematics, Stockholm University, Sweden.

She has been working with Vattenfall R\&D Team analytics since 2018 as a data scientist and consultan from $\AA \mathrm{F}$. She has strong background and extensive experience in statistics, financial mathematics, data analytics and machine learning. During her academia and industry work, she has gained considerable expertise in the fields of macroeconomic forecasting, financial fraud detection and configuration, bioinformatics, population dynamics, energy efficiency and automation by developing data-driven solutions. Her master and licentiate theses are available as research reports in the mathematical statistics series on DiVA. 